\title{
Alternative therapies in exudative age related macular degeneration
}

\author{
N H Victor Chong, Alan C Bird
}

Age related macular degeneration (AMD) is the leading cause of blindness in the developed world. ${ }^{1}$ Vision may be lost as a consequence of choroidal neovascularisation (CNV), detachment of the retinal pigment epithelium (RPE), or geographic atrophy. Therapeutic efforts have been directed towards influencing the neovascular process, which is acknowledged to be the most common cause of visual loss.

The beneficial effect of laser photocoagulation in well defined "classic" juxtafoveal and perifoveal CNV is well established and widely accepted. ${ }^{23}$ However, they comprise a small proportion of those with visual loss in clinical practice $(<10 \%),{ }^{4}$ and recurrence rates of up to $59 \%$ after treatment have been reported. ${ }^{5}$ At best, photocoagulation delays severe visual loss rather than representing a permanent cure in the majority of cases.

The treatment of subfoveal CNV with laser is more controversial..$^{6-8}$ Despite immediate loss of acuity, long term follow up of more than 2 years has shown benefit in patients with small new vessel complexes and poor visual acuity. ${ }^{9}$ Nevertheless, the sudden acquisition of a dense central scotoma allows little time for the treated patients to adapt to the visual changes, and this treatment has yet to become widely practised.

There is clearly a need for new forms of treatment for subfoveal $\mathrm{CNV}$ in $\mathrm{AMD}$, and many alternative approaches have been considered. This review outlines the current status of these alternative therapies.

\section{Radiation therapy}

The rationale of radiation therapy is based on the observation that growing blood vessels are more sensitive to damage by ionising radiation than mature vessels, ${ }^{10}$ so that new vessels may become non-perfused without damage to surrounding tissue. This can be achieved by either an external beam (teletherapy) or an episcleral plaque (brachytherapy).

In 1993, Chakravarthy and colleagues first reported a study of external beam radiation therapy in 19 AMD patients with subfoveal $\mathrm{CNV}$ and visual acuity no better than $6 / 24 .^{11}$ This was a non-randomised clinical trial, but seven patients who declined treatment were used for comparison. The patients received either 10 or $15 \mathrm{~Gy}$ in five equal fractions. Visual acuity was maintained or improved in 15 of the 19 treated patients $(78 \%)$ at 6 months and 12 of the $19(63 \%) 1$ year following therapy, whereas only one of the seven untreated controls (14\%) maintained this level of visual acuity at 1 year. No radiation induced retinopathy or optic neuropathy was reported. There was no statistically significant difference between the groups receiving either 10 or 15 Gy. Since then, a number of nonrandomised clinical trials have been reported using either external beam radiation, proton beam radiation, or episcleral plaques delivering between 5 Gy to 24 Gy in either a single fraction or up to eight fractions. The proportion whose visual acuity was maintained or improved ranged from $40 \%$ to $80 \%$ with mean follow up more than 6 months. ${ }^{12-14}$

A number of randomised prospective studies are in progress to prove the efficacy and safety of this treatment, and elective use of radiation must await the results of these trials.

\section{Photodynamic therapy (PDT)}

Photosensitised target tissue is selectively destroyed by light at a wavelength corresponding to an absorption peak of the photosensitising agent. Photoexcitation of the photosensitiser causes conversion of the singlet ground state to the excited triplet state. Release of free radical intermediates from the triplet state causes structural and functional damage to cell membranes and other structures leading to cell death. Alternatively, the energy transfers to molecular oxygen forming singlet oxygen that reacts with proteins, lipids, and nucleic acids of the cell leading to cell death. ${ }^{15}$

Benzoporphyrin derivative monoacid (BPD) had been shown to be safe for human use in clinical trials for malignant skin tumours. ${ }^{16} \mathrm{~A}$ liposomal preparation of BPD was adopted for ophthalmic work, since it was hoped that the dye would be preferentially taken up by the growing new vessels. ${ }^{17}$ This photosensitiser has a long absorption wavelength at $692 \mathrm{~nm}^{18}$ allowing deeper tissue penetration through blood, fluid, and fibrous tissue. In non-human primates, closure of CNV was seen in eyes 4 weeks after PDT. In eyes without CNV, the choriocapillaris was typically occluded at 24 hours after PDT with damage to the RPE in all cases. The photoreceptors showed mild pyknosis and the outer segments showed disarray and vacuolation. The medium and larger choroidal vessels and inner retina appeared normal. After 4 weeks, the choriocapillaris was reperfused; there was some functional recovery of the RPE and the photoreceptors remained mildly disorganised. ${ }^{15}$

In a phase I/II clinical trial 107 patients with CNV were treated with PDT using liposomal BPD (6 or $12 \mathrm{mg} / \mathrm{m}^{2}$ ) for subfoveal CNV. Irradiation was given 10-30 minutes after the start of the dye infusion using a diode laser (689 $\mathrm{nm}$ ) with light doses of $600 \mathrm{~mW} / \mathrm{cm}^{2}$ and $25-150 \mathrm{~J} / \mathrm{cm}^{2}$. At 1 week, the choriocapillaris and CNV were non-perfused. At 4 and 12 weeks, angiographic leakage reappeared in most cases with all regimens. ${ }^{19}$ The same group of investigators then carried out multiple treatment in 48 patients with light doses of $100 \mathrm{~J} / \mathrm{cm}^{2}$ after the administration of 6 $\mathrm{mg} / \mathrm{m}^{2}$ of liposomal BPD at 2,4 , or 8 week intervals. Partial recurrence was still common at 12 weeks after the last treatment but the area of leakage from recurrence was reduced with retreatment and the patients maintained surprisingly good vision. ${ }^{20}$ Multiple treatments using higher 
dosage (12 or $18 \mathrm{mg} / \mathrm{m}^{2}$ ) of liposomal BPD in normal primates have shown significant damage to the normal retina, choroid, and optic nerve. ${ }^{21}$

It appears that PDT causes occlusion of CNV for at least a short time, and retreatment up to three times reduces area of leakage. Current randomised controlled trials will show the potential influence on visual prognosis.

\section{Submacular surgery with or without RPE transplantation}

Advances in vitreoretinal techniques have allowed the removal of submacular CNV. In 1992, Lambert and colleagues first reported 10 cases of surgical removal of subfoveal $\mathrm{CNV}^{22}$ The postoperative visual results at 6 months ranged from $6 / 30$ to counting fingers, with the majority having $6 / 60$ or worse. Thomas and colleagues reported the largest series to date of 41 cases in $1994 .^{23}$ Only two eyes regained a visual acuity of $6 / 12$ or better, and only $12 \%$ had an improvement of visual acuity. The final visual acuity was $6 / 60$ or worse in $88 \%$ of the patients. These results were not obviously better than those expected from the natural history of the disease, and were disappointing when compared with results of surgery in cases with presumed ocular histoplasmosis (POHS). ${ }^{23}$ Gass provided a potential explanation for this when he described two growth patterns of $\mathrm{CNV}^{24}$ In type $1 \mathrm{CNV}$ the new vessels are external to the RPE, and typically occur in eyes with AMD. Type $2 \mathrm{CNV}$ grows in the subretinal space, thus leaving native RPE in direct contact with Bruch's membrane. Young patients are more likely to have type $2 \mathrm{CNV}$. In the first case removal of the RPE would occur at surgery, whereas on the second the RPE would be left in situ. Furthermore, AMD is often associated with RPE dysfunction and diffuse Bruch's membrane disease when compared with focal disease in POHS. It is possible that healthy and younger RPE might recover from the surgically induced defect more readily.

Using current techniques, submacular surgery appears not to be an effective option in subfoveal CNV in AMD. RPE cell transplantation might be used to cover the defect, and has been attempted in five patients with subfoveal $\mathrm{CNV}$ in AMD. ${ }^{25}$ All five were shown to fixate over the RPE graft immediately after surgery using scanning laser ophthalmoscope microperimetric technique. However, an absolute scotoma developed over the transplant several months postoperatively, and there was chronic oedema of the overlying retina. The RPE graft might have been rejected and destroyed, or the transplantation may not have survived on the abnormal Bruch's membrane. However, the presence of persistent oedema implies that the RPE survived since, in its absence, retinal atrophy would have been expected. ${ }^{26}$ It seems most likely that the RPE survived but functioned abnormally. The key to success would be long term survival of the transplanted RPE that had normal function, which might require a healthy Bruch's membrane or an appropriate substrate. There are still a large number of hurdles to be overcome before clinical trial is appropriate.

\section{Drug therapy}

Increasing knowledge of the properties of new vessels and their requirements for growth has given hope of alternative forms of therapy. Several approaches are available by which the behaviour of CNV might be modified by drug therapy.

INTERFERON

Interferon inhibits the migration and proliferation of vascular endothelial cells, which are important for angiogenesis. When administered to non-human primates with experimentally induced retinal hypoxia, interferon caused regression of iris neovascularisation. ${ }^{27}$ Based on these observations, a number of non-randomised trials showed promise. However, a prospective randomised placebo controlled trial involving 481 patients failed to demonstrate significant benefit. ${ }^{28}$

\section{VASCULAR ENDOTHELIAL GROWTH FACTOR}

Vascular endothelial growth factor (VEGF) has been shown to play an important role in retinal and iris neovascularisation caused by retinal ischaemia. ${ }^{29}$ It is expressed in response to retinal cell hypoxia, and behaves as an endothelial specific mitogen in vivo. ${ }^{30}$ The inhibition of VEGF by antisense prevents experimental iris and retinal neovascularisation, ${ }^{31}{ }^{32}$ and injection of VEGF into normal non-human primate eyes produces iris neovascularisation, neovascular glaucoma, and the proliferation of retinal blood vessels. ${ }^{33}$ Anti-VEGF might play a significant role in the future management of proliferative disease as part of diabetic retinopathy, and as a result of retinal ischaemia from other causes. Its potential role in $\mathrm{CNV}$ in the context of AMD is less clear. Intravitreal levels of VEGF are elevated in patients with $\mathrm{CNV}^{34}$ and VEGF is presented in surgically removed CNV. ${ }^{35} \mathrm{RPE}$ expression of VEGF is also increased in AMD. ${ }^{36}$ Orally administered protein kinase $\mathrm{C} \beta$ selective inhibitor blocks VEGF induced retinal permeability. ${ }^{37}$ Its use in suppressing VEGF induced angiogenesis merits further investigation.

\section{INTEGRINS}

There is evidence that more than one cytokine dependent pathway of angiogenesis exists, and each can be defined by its dependency on distinct vascular cell integrins. In vivo angiogenesis induced by basic fibroblast growth factor (bFGF) or by tumour necrosis factor alpha (TNF- $\alpha$ ) depend upon $\alpha_{v} \beta_{3}$, whereas angiogenesis initiated by VEGF or by transforming growth factor alpha (TGF- $\alpha$ ) are associated with expression of $\alpha_{v} \beta_{5}{ }^{38}$ Interestingly, $\alpha_{v} \beta_{3}$ was observed on CNV from patients with AMD, ${ }^{39}$ but both integrins $\alpha_{v} \beta_{3}$ and $\alpha_{v} \beta_{5}$ were present in retinal neovascularisation in proliferative diabetic retinopathy. Systemically administered cyclic peptide antagonist of integrins $\alpha_{v} \beta_{3}$ and $\alpha_{v} \beta_{5}$ not only stops vessel growth, but induces endothelial cell death in new blood vessels, and yet there is no influence on mature blood vessels. ${ }^{39}$ The role of these agents in the future management of $\mathrm{CNV}$ is uncertain, but they hold promise.

\section{THALIDOMIDE}

Thalidomide is a potent teratogen causing limb defects. These effects may be consequent upon suppression of blood vessel growth in the developing fetal limb bud. It decreases the expression of integrin $\beta$ subunits, most notably $\beta_{3}$ and $\beta_{2}{ }^{40}$ Orally administered thalidomide inhibits corneal neovascularisation in rabbit. ${ }^{41}$ However, thalidomide has to be given intraperitoneally to inhibit VEGF induced corneal neovascularisation in rodents. ${ }^{42}$ Its role in treating or prevention of CNV has yet to be tested.

\section{Prophylactic treatment}

$\mathrm{AMD}$ is difficult to treat once $\mathrm{CNV}$ is established. In future, prevention of visual loss might be achieved by prophylaxis to prevent the formation of CNV. This could be directed to those with age changes at the level of Bruch's membrane known to imply high risk of visual loss. Many clinicians have observed that drusen disappear after focal laser therapy to the posterior pole. ${ }^{43}$ As CNV is believed to occur in response to age change in Bruch's membrane, resolution of these changes might intuitively be expected to lower the incidence of CNV. The idea of using a small number of threshold laser spots to cause resolution of 
drusen, and as a prophylactic therapy for AMD, has attracted considerable interest. In one study such patients were treated with 12 argon laser lesions in the posterior pole, with review for $12-24$ months. ${ }^{44} \mathrm{CNV}$ developed in one patient 8 months after treatment, with consequent loss of central vision. One patient lost three lines of vision due to geographic atrophy after 12 months. In nine of the remaining 10 patients, high risk characteristics of drusen were reduced, and maintained $6 / 12$ visual acuity at 12 months.

The CNV prevention trial is a multicentre randomised prospective trial using up to 40 laser spots for treating high risk eyes in AMD patients. ${ }^{45}$ In the initial report of 276 patients, age changes, such as drusen, were modified by the therapy, but there was an increase rate of CNV formation with no benefit to visual acuity at 12 months. By contrast, a controlled study undertaken in Sweden appeared to show benefit, although the control group had a surprising high incidence of visual loss. ${ }^{46}$

\section{Conclusion}

Many forms of treatment have been devised with the objective of destroying or suppressing subretinal new vessel growth. None of these is likely to have a significant impact on blindness due to AMD. There is urgency to identify the new therapeutic avenues. It appears likely that good vision will depend upon survival of the RPE/photoreceptor complex. Any therapeutic agent or manoeuvre directed against new blood vessels must not interfere with the limited potential for RPE repair. Thus, the success of a medical agent would depend upon its ability to suppress blood vessel growth or cause endothelial cell death without associated effect on the RPE.

NHVC is supported by the MRC clinical training fellowship. N H VICTOR CHONG ALAN C BIRD

Department of Clinical Ophthalmology, Institute of Ophthalmology (UCL), Moorfields Eye Hospital, London

Correspondence to: Mr Victor Chong, Professorial Unit, Institute of Ophthalmology (UCL), Moorfields Eye Hospital, City Road, London EC1V 2PD.

1 Evans J, Rooney C, Ashwood F, et al. Blindness and partial sight in England and Wales: April 1990-March 1991. Health Trends 1996;28:5-12.

2 Macular Photocoagulation Study Group. Argon laser photocoagulation for neovascular maculopathy. Three-year results from randomized clinical neovascular maculopathy. Three-year resut

3 Macular Photocoagulation Study Group. Krypton laser photocoagulation for neovascular lesions of age-related macular degeneration. Results of a randomized clinical trial. Arch Ophthalmol 1990;108:816-24.

4 Freund KB, Yannuzzi LA, Sorenson JA. Age-related macular degeneration and choroidal neovascularization. Am f Ophthalmol 1993;115:786-91.

5 Macular Photocoagulation Study Group. Recurrent choroidal neovascularization after argon laser photocoagulation for neovascular maculopathy. Arch Ophthalmol 1986;104:503-12.

6 Macular Photocoagulation Study Group. Subfoveal neovascular lesions in age-related macular degeneration. Guidelines for evaluation and treatment in the macular photocoagulation study. Arch Ophthalmol 1991;109:124257.

7 Macular Photocoagulation Study Group. Laser photocoagulation of subfoveal recurrent neovascular lesions in age-related macular degeneration. Results of a randomized clinical trial. Arch Ophthalmol 1991;109: tion. Result

8 Macular Photocoagulation Study Group. Laser photocoagulation of Macular Photocoagulation Study Group. Laser photocoagulation of
subfoveal neovascular lesions in age-related macular degeneration. Results subfoveal neovascular lesions in age-related macular degeneration.
of a randomized clinical trial. Arch Ophthalmol 1991;109:1220-31.

9 Macular Photocoagulation. Study Group. Laser photocoagulation of subfoveal neovascular lesions of age-related macular degeneration. Updated findings from two clinical trials. Arch Ophthalmol 1993;111:12009.

10 Archer DB, Amoaku WMK, Gardiner TA. Radiation retinopathy, clinical, histological and ultrastructural correlation. Eye 1991;5:239-51.

11 Chakravarthy U, Houston RF, Archer DB. Treatment of age-related subfoveal neovascular membranes by teletherapy: a pilot study. $\mathrm{Br} \mathcal{F}$ Ophthalmol 1993;77:265-73.

12 Bergink GJ, Deutman AF, van-den BJ, et al. Radiation therapy for age-related subfoveal choroidal neovascular membranes. A pilot study. Doc Ophthalmol 1995;90:67-74.
13 Finger PT, Berson A, Sherr D, et al. Radiation therapy for subretinal neovascularization. Ophthalmology 1996;103:878-89.

14 Hollick EJ, Goble RR, Knowles PJ, et al. Radiotherapy treatment of age-related subfoveal neovascular membranes in patients with good vision. Eye 1996;10:609-16.

15 Husain D, Miller JW. Photodynamic therapy of exudative age-related macular degeneration. Semin Ophthalmol 1997;12:14-25.

16 Lui H, Anderson RR. Photodynamic therapy in dermatology: recent developments. Dermatol Clin 1993;11:1-13.

17 Kramer M, Miller JW, Michaud N, et al. Liposomal benzoporphyrin derivative verteporfin photodynamic therapy. Selective treatment of choroidal neovascularization in monkeys. Ophthalmology 1996;103:427-38.

18 Richter A, Waterfield E, Jain A, et al. Photosensitizing potency of structural analogs of benzoporphyrin derivative (BPD-MA) in a mouse model. $\mathrm{Br} \mathcal{F}$ Cancer 1991;63:87-93.

19 Gragoudas ES, Schmidt-Erfurth U, Sickenberg M, et al. Results and preliminary dosimetry of photodynamic therapy for choroidal neovascu(Suppl) 1997;38:73.

20 Schmidt-Erfurth U, Miller JW, Sickenberg M, et al. Photodynamic therapy for choroidal neovascularisation in a phase I/II study: preliminary results of multiple treatments. Invest Ophthalmol Vis Sci (Suppl) 1997;38:74.

21 Reinke MH, Canakis C, Husain D, et al. Photodynamic therapy (PDT) retreatment of normal retina and choroid in the primate. Invest Ophthalmol Vis Sci (Suppl) 1997;38:75.

22 Lambert HM, Capone A, Aaberg TM, et al. Surgical excision of subfoveal neovascular membranes in age-related macular degeneration. $\mathrm{Am} f$ Ophthalmol 1992;113:257-62.

23 Thomas MA, Dickinson JD, Melberg NS, et al. Visual results after surgical removal of subfoveal choroidal neovascular membranes. Ophthalmology 1994;101:1384-96.

24 Gass JD. Biomicroscopic and histopathologic considerations regarding the feasibility of surgical excision of subfoveal neovascular membranes. Am f Ophthalmol 1994;118:285-98.

25 Algvere PV, Berglin L, Gouras P, et al. Transplantation of fetal retinal pigment epithelium in age related macular degeneration with subfoveal neovascularization. Graefes Arch Clin Exp Ophthalmol 1994;232:707-16.

26 Foulds WS. Do we need a retinal pigment epithelium (or choroid) for the maintenance of retinal apposition? Br f Ophthalmol 1985;69:237-9.

27 Miller JW, Stinson WG, Folkman J. Regression of experimental iris neovascularization with systemic alpha-interferon. Ophthalmology 1993;100:9-14.

28 Pharmacological Therapy for Macular Degeneration Study Group. Interferon alfa-2a is ineffective for patients with choroidal neovascularization secondary to age-related macular degeneration. Results of a prospective randomized placebo-controlled clinical trial. Arch Ophthalmol 1997;115:865-72.

29 Tolentino MJ, Miller JW, Gragoudas ES, et al. Vascular endothelial growth factor is sufficient to produce iris neovascularization and neovascular glaucoma in a nonhuman primate. Arch Ophthalmol 1996;114:964-70.

30 Vinores SA, Youssri AI, Luna JD, et al. Upregulation of vascular endothelial growth factor in ischemic and non-ischemic human and experimental retinal disease. Histol Histopathol 1997;12:99-109.

31 Adamis AP, Shima DT, Tolentino MJ, et al. Inhibition of vascular endothelial growth factor prevents retinal ischemia-associated iris neovascularization in a nonhuman primate. Arch Ophthalmol 1996;114:66-71.

32 Aiello LP, Pierce EA, Foley ED, et al. Suppression of retinal neovascularization in vivo by inhibition of vascular endothelial growth factor (VEGF) using soluble VEGF-receptor chimeric proteins. Proc Natl Acad Sci USA 1995;92:10457-61.

33 Ozaki H, Hayashi $\mathrm{H}$, Vinores SA, et al. Intravitreal sustained release of VEGF causes retinal neovascularization in rabbits and breakdown of the blood-retinal barrier in rabbits and primates. Exp Eye Res 1997;64:505-17.

34 Wells JA, Murthy R, Chibber R, et al. Levels of vascular endothelial growth factor are elevated in the vitreous of patients with subretinal neovascularisation. Br f Ophthalmol 1996;80:363-6.

35 Kvanta A, Algvere PV, Berglin L, et al. Subfoveal fibrovascular membranes in age-related macular degeneration express vascular endothelial growth factor. Invest Ophthalmol Vis Sci 1996;37:1929-34.

36 Kliffen M, Sharma HS, Mooy CM, et al. Increased expression of angiogenic growth factors in age-related maculopathy. Br f Ophthalmol 1997;81:15462.

37 Aiello LP, Bursell SE, Clermont A, et al. Vascular endothelial growth factorinduced retinal permeability is mediated by protein kinase $C$ in vivo and suppressed by an orally effective beta-isoform-selective inhibitor. Diabetes

38 Friedlander M, Brooks PC, Shaffer RW, K et al. Definition of two angiogenic pathways by distinct alpha v integrins. Science 1995;270:1500-2.

39 Friedlander $M$, Theesfeld CL, Sugita $M$, et al. Involvement of integrins alpha v beta 3 and alpha v beta 5 in ocular neovascular diseases. Proc Natl Acad Sci USA 1996;93:9764-9.

40 McCarty MF. Thalidomide may impede cell migration in primates by down-regulating integrin beta-chains: potential therapeutic utility in solid malignancies, proliferative retinopathy, inflammatory disorders, neointimal hyperplasia, and osteoporosis. Med Hypothes 1997;49:123-31.

41 D'Amato RJ, Loughnan MS, Flynn E, et al. Thalidomide is an inhibitor of angiogenesis. Proc Natl Acad Sci USA 1994;91:4082-5.

42 Kenyon BM, Browne F, D'Amato RJ. Effects of thalidomide and related metabolites in a mouse corneal model of neovascularization. Exp Eye Res 1997;64:971-8.

43 Figueroa MA, Regueras A, Bertrand J. Laser photocoagulation to treat macular soft drusen in age related macular degeneration. Retina 1994;14:391-6.

44 Guymer RH, Gross JM, Owens SL, et al. Laser treatment in subjects with high-risk clinical features of age-related macular degeneration. Posterior pole appearance and retinal function. Arch Ophthalmol 1997;115:595-603.

5 Choroidal neovascularization prevention trial research group. Laser treatment in eyes with large drusen. Ophthalmology 1998;105:11-23.

46 Frennesson IC, Nilsson SE. Laser photocoagulation of soft drusen in early age-related maculopathy (ARM). The one-year results of a prospective, randomised trial. Eur f Ophthalmol 1996;6:307-14. 